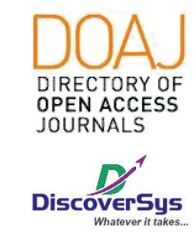

Published by DiscoverSys

\title{
Pneumotoraks spontan primer berulang pada wanita hamil dengan hiperemesis gravidarum: laporan kasus
}

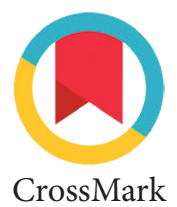

Ni Putu Ayu Widiasari, ${ }^{1 *}$ Ni Luh Putu Eka Arisanti, ${ }^{2}$ Ida Bagus Ngurah Rai ${ }^{2}$

\section{ABSTRACT}

Background: Spontaneous pneumothorax is a rare case during pregnancy. However, the condition of Hyperemesis Gravidarum during pregnancy is one of the risk factors for recurrent primary spontaneous pneumothorax.

Case Description: A 28-year-old woman with G5P3013 gestational age 12-13 weeks with Hyperemesis Gravidarum had complaints of tightness and recurrent acute pleuritic chest pain. After a clinical and supporting examination using ultrasound, patients were diagnosed with recurrent primary spontaneous pneumothorax, and observational and symptomatic treatments were performed. The rupture of the bleb or the subpleura bulla is thought to be a pathological mechanism. Patients given birth vaginally without complications and complete resolution of the pneumothorax occurred.

Conclusion: Recurrent pneumothorax in pregnant women with a history of hyperemesis gravidarum is rare. Observational and symptomatic treatment is the initial treatment that can be done.

Keywords: Spontaneous pneumothorax, pregnancy, hyperemesis gravidarum

Cite This Article: Widiasari, N.P.A., Arisanti, N.L.P.E., Rai, I.B.N. 2019. Pneumotoraks spontan primer berulang pada wanita hamil dengan hiperemesis gravidarum: laporan kasus. Intisari Sains Medis 10(1): 114-119. D0I: 10.1556/ism.v10i1.321

ABSTRAK

Latar belakang: Pneumotoraks spontan merupakan kasus yang jarang terjadi pada masa kehamilan. Akan tetapi keadaan Hiperemesis Gravidarum selama masa kehamilan merupakan salah satu faktor risikonya terjadinya pneumotoraks spontan primer berulang.

Deskripsi Kasus: Seorang wanita berusia 28 tahun dengan G5P3013 umur kehamilan 12 - 13 minggu dengan Hiperemesis Gravidarum mengalami keluhan sesak dan nyeri dada pleuritik akut berulang. Setelah dilakukan Pemeriksaan klinis dan penunjang menggunakan
USG, pasien didiagnosis dengan Pneumotoraks spontan primer berulang, dan dilakukan penanganan observasional dan simtomatis. Pecahnya bleb atau bula subpleura diduga sebagai mekanisme patologisnya. Pasien melahirkan pervaginam tanpa komplikasi dan terjadi resolusi sempurna dari Pneumotoraks.

Kesimpulan: Kejadian pneumotoraks berulang pada wanita hamil dengan riwayat hyperemesis gravidarum merupakan hal yang jarang terjadi. Penanganan observasional dan simtomatis merupakan tatalaksana awal yang dapat dilakukan.
${ }^{1}$ Fakultas Kedokteran Universitas Udayana, Bali, Indonesia 2Departemen IImu Penyakit Paru, RSUP Sanglah/Fakultas Kedokteran Universitas Udayana, Bali, Indonesia

\section{*Korespondensi:}

Ni Putu Ayu Widiasari, Fakultas

Kedokteran Universitas Udayana,

Bali, Indonesia

ayu.widiasari@yahoo.com

Received: 2018-10-03

Accepted: 2018-11-04

Published: 2019-04-01
Kata Kunci: Pneumotoraks spontan, kehamilan, hiperemesis gravidarum

Cite Pasal Ini: Widiasari, N.P.A., Arisanti, N.L.P.E., Rai, I.B.N. 2019. Pneumotoraks spontan primer berulang pada wanita hamil dengan hiperemesis gravidarum: laporan kasus. Intisari Sains Medis 10(1): 114-119. D0I: 10.1556/ism.v10i1.321

\section{LATAR BELAKANG}

Pneumotoraks merupakan istilah untuk mendeskripsikan terisinya ruang pleura oleh udara. Pneumotoraks yang terjadi tanpa adanya riwayat trauma dada disebut sebagai Pneumotoraks Spontan (PS). PS hingga saat ini belum dapat diketahui pasti penyebabnya. Pecahnya bleb atau bula pada apeks paru diindikasikan menjadi faktor pemicu dari PS tersebut. ${ }^{1}$

PS pada wanita hamil merupakan kasus yang sangat jarang terjadi. Hingga saat ini belum terdapat informasi mengenai prevalensi maupun insiden kasus tersebut di dunia. Pada laporan kasus dan tinjuan pustaka yang ditulis oleh Gupta dkk tahun 2013 disebutkan bahwa hanya terdapat 57 kasus PS pada kehamilan yang dilaporkan hingga tahun tersebut. ${ }^{2}$ Berdasarkan atas laporan serial kasus yang ditulis oleh Wong dkk tahun 2006 mendapatkan bahwa sebagian besar kasus PS pada wanita hamil yang dilaporkan merupakan pneumotoraks berulang tanpa penyebab yang diketahui. Pada artikel tersebut juga disebutkan bahwa Lymphangiomyomatosis (LAM) dan hiperemesis gravidarum merupakan faktor risiko yang harus dipikirkan sebagai pencetus PS pada wanita hamil. 
Keadaan atau posisi manuver valsava yang dapat meningkatkan tekanan intratorakal seperti batuk, bersin, defekasi, muntah, dan masa persalinan dapat menjadi pemicu pneumotoraks atau pneumomediastinum pada wanita hamil. ${ }^{3}$

Selama kehamilan terjadi perubahan fisiologis pada fungsi paru, seperti menurunannya cadangan fungsional paru, termasuk kapasitas residual paru dan kapasitas paru total. Pada kehamilan juga tejadi peningkatan konsumsi oksigen oleh plasenta, fetus, dan organ maternal. Adanya anemia fisiologis pada kehamilan dan tekanan parsial oksigen yang relatif rendah pada vena umbilikal, menyebabkan keadaan hipoksia pada ibu hamil tidak dapat ditoleransi. ${ }^{4}$ Gangguan ventilasi khususnya yang terjadi pada PS dapat memberikan dampak yang serius bagi ibu dan janin. Fakta tersebut dan prognosis PS yang bergantung pada kualitas penanganan menjadikan informasi mengenai patofisiologi hingga terapi PS pada ibu hamil merupakan sebuah urgensi. ${ }^{5}$ Oleh karena itulah pada laporan kasus ini, kami mencoba untuk melaporkan kasus Pneumotoraks spontan primer berulang pada ibu hamil dengan usia kehamilan 12-13 minggu dan mengalami hiperemesis gravidarum dimana berfokus pada gambaran kasus yang terjadi.

\section{LAPORAN KASUS}

Wanita 28 tahun dengan G5P3013 umur kehamilan 12 - 13 minggu datang ke poliklinik paru (17 Januari 2018) dengan keluhan sesak sejak lima hari sebelum datang ke poliklinik (12 Januari 2018). Sesak dikatakan timbul tiba-tiba ketika pasien mengalami mual dan muntah hebat. Sesak disertai dengan nyeri dada yang memberat ketika pasien menarik napas. Selama mengalami keluhan, pasien tetap dapat melakukan aktifitas sehari-hari. Saat ini keluhan sesak dan nyeri dada sudah membaik. Pasien mengalami keluhan mual dan muntah yang dipengaruhi oleh kehamilan dan rutin melakukan kontrol ke dokter spesialis kandungan. Saat ini keluhan mual dan muntah sudah membaik. Keluhan lain seperti batuk lama, batuk darah, demam, menggigil, dan keluhan pada kehamilan dikatakan tidak ada. Pasien pertama kali mengalami keluhan seperti ini. Pasien tidak memiliki riwayat penyakit paru-paru, penyakit jantung, darah tinggi, dan diabetes mellitus. Pasien memiliki riwayat Hiperemesis Gravidarum pada kehamilan sebelumnya hingga membutuhkan perawatan di rumah sakit. Ibu pasien memiliki riwayat Hiperemesis Gravidarum pada kehamilannya. Ayah dan suami pasien adalah perokok aktif sehingga pasien merupakan seorang perokok pasif sejak kecil. Pasien merupakan seorang pegawai swasta dan tidak terdapat teman pasien yang mengalami keluhan serupa. Pada tanggal 13 Januari 2018 pasien telah menjalani pemeriksaan oleh dokter spesialis obstetri dan ginekologi dan dinyatakan tidak terdapat tanda fetal distress.

Pada pemeriksaan ditemukan keadaan umum pasien sakit sedang, kesadaran kompos mentis, tanda vital sebagai berikut: Nadi $101 \mathrm{x} /$ menit, laju pernapasan $22 \mathrm{x} / \mathrm{menit}$, Tekanan darah $110 / 70 \mathrm{mmHg}$, temperatur aksila $36,4^{\circ} \mathrm{C}, \mathrm{SpO} 2$ 98\% udara ruangan, skala nyeri 1. Pemeriksaan fisik umum didapatkan gerakan paru kanan tertinggal dengan penurunan suara napas paru kanan dan pekrusi hipersonor pada paru kanan, tidak ditemukan tanda sianosis perifer dan sentral.

Pasien telah membawa beberapa hasil pemeriksaan penunjang sebelumnya, yaitu pemeriksaan USG toraks, foto toraks PA, dan spirometri. Pada foto toraks PA tanggal 13 Januari 2018 ditemukan gambaran luscen pada hemitoraks kanan dengan gambaran paru yang kolaps total (Gambar 1). USG toraks dilakukan pada tanggal 13 Januari 2018 menunjukkan tidak terdapat gambaran pleura visceralis di hemitoraks kanan dan tidak terdapat pergerakan pleura visceralis kanan (Gambar 2). Pada pemeriksaan spirometri tanggal 15 Januari 2018 menunjukkan adanya retriksi sedang. Berdasarkan atas keluhan klinis dan pemeriksaan fisik, pasien diputuskan untuk menjalani observasi ketat di rumah sakit, namun karena pasien menolak akhirnya observasi dilakukan di rumah dengan pemberian edukasi.

Setelah dilakukan observasi selama dua minggu pasien kembali ke poliklinik untuk kontrol. Hasil foto toraks pada tanggal 27/01/2018 menunjukkan terdapat perbaikan kondisi paru dibandingkan hasil sebelumnya. Tampak luas area luscen berkurang dan paru yang mulai mengembang. Setelah dilakukan observasi kembali selama 1 minggu, secara klinis pasien membaik, keluhan sesak dan nyeri dada dikatakan tidak ada, hemodinamik stabil, pemeriksaan fisik didapatkan gerakan dada simetris, suara paru kanan dan kiri positif dengan perkusi sonor dikedua paru.

Pada tanggal 8 Juni 2018, pasien datang ke poliklinik untuk melakukan kontrol. Pasien mengeluh mengalami nyeri dada pleuritik tanpa disertai sesak. Keluhan lain dikatakan tidak ada. Keluhan dirasakan tiba-tiba setelah pasien kelelahan melakukan kegiatan di banjar. Pada pemeriksaan ditemukan hemodinamik stabil dengan SpO2 98\% udara ruangan. Terdapat penurunan suara paru kanan dengan penurunan taktil fremitus dan perkusi hipersonor pada paru kanan. Pasien menolak untuk melakukan foto toraks. Setelah melakukan diskusi dengan pasien dan mempertimbangkan kondisi klinis pasien, diputuskan untuk melakukan observasi selama satu minggu di rumah pasien. 
Tabel 1 Hasil spirometri pasien yang dilakukan pada tangal 15 Januari 2018

\begin{tabular}{lcccc}
\hline Data Demografis & \multicolumn{3}{c}{ Hasil Pemeriksaan } \\
\hline Tinggi Badan (cm) Berat Badan (kg) & \multicolumn{4}{c}{$156 \mathrm{~cm}$} \\
Ras & \multicolumn{4}{c}{$46 \mathrm{~kg}$} \\
Perokok & \multicolumn{4}{c}{ Asiatik } \\
Pred & \multicolumn{4}{c}{ Tidak } \\
Parameter Spirometri & LAM/Polgar & Pred & Test & \%Pred \\
FVC & L & 3.01 & 1.66 & 55.0 \\
FEV 1 & L & 2.69 & 1.48 & 54.9 \\
FIVC/FVC & $\%$ & 100.0 & - & - \\
\hline
\end{tabular}

Interpretasi : Retriksi sedang

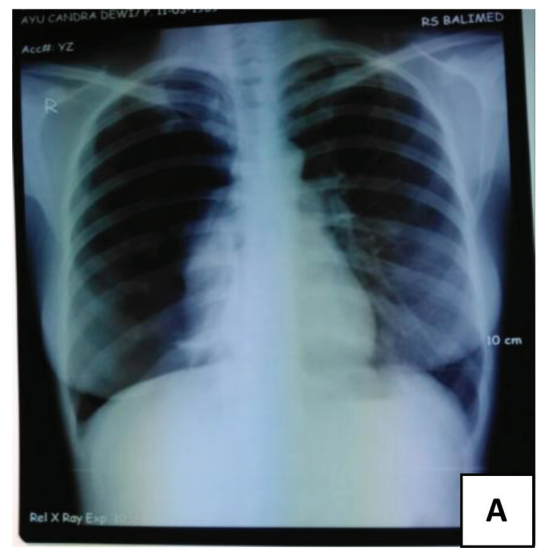

Gambar 1 Perkembangan status

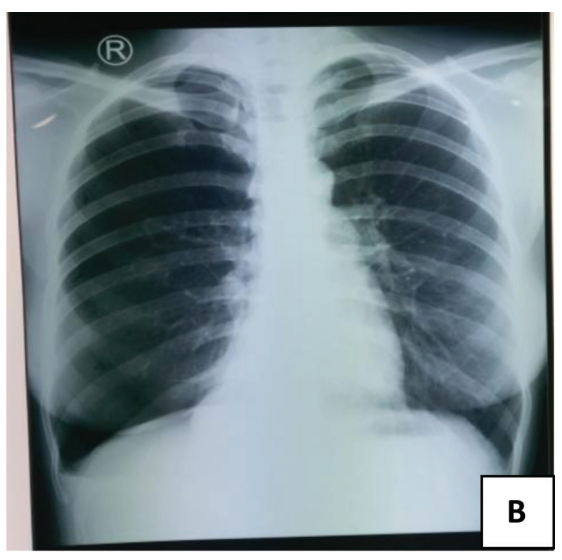

pneumotoraks spontan pasien berdasarkan gambaran radiologi toraks Postero-Anterior (PA). (A) Pneumotoraks dextra dengan kolap total paru kanan pada pemeriksaan awal (13/01/2018). (B) Pneumotoraks dextra dengan pengembangan paru kanan parsial (27/01/2018)

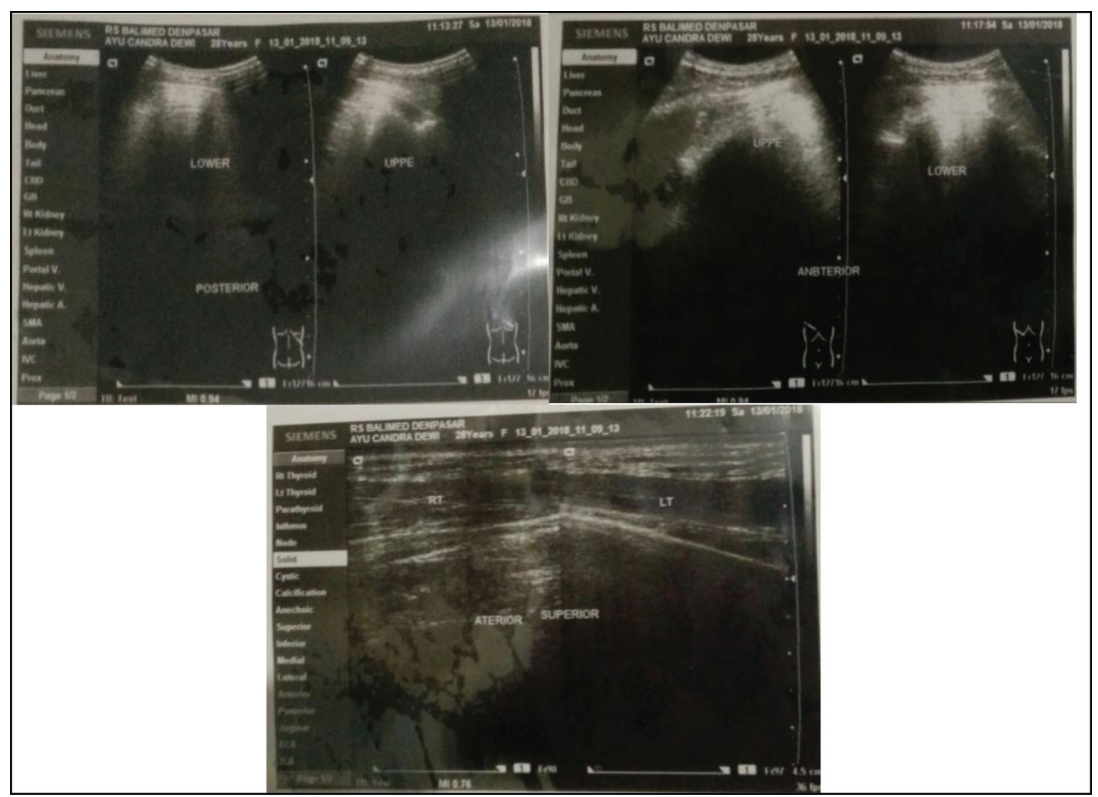

Gambar 2 USG toraks (13/01/2018) menunjukkan tidak terdapat gambaran pleura visceralis di hemitoraks dextra serta juga tidak terdapat pergerakan pleura visceralis dextra

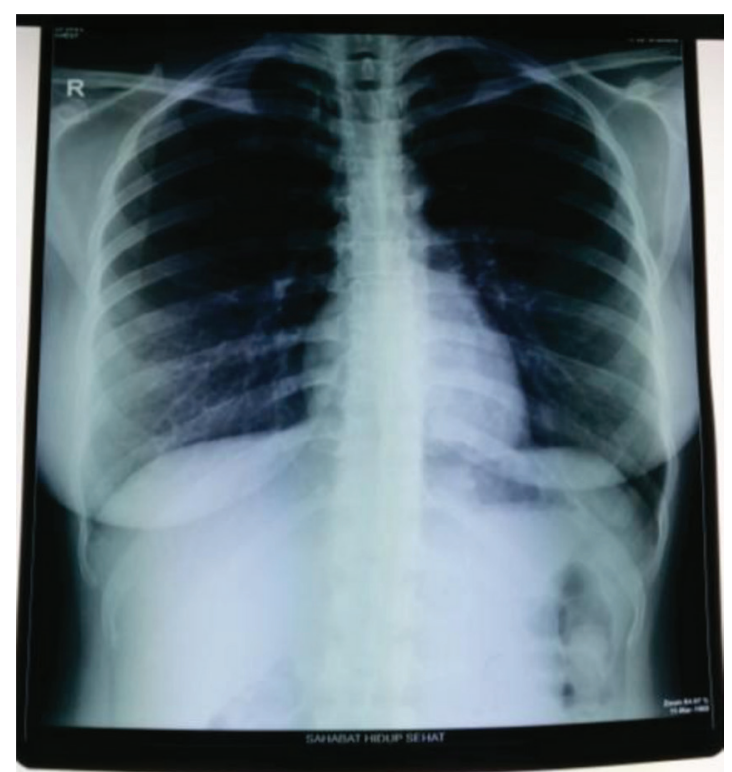

Gambar 3 Foto Toraks PA (27/01/2018) menunjukkan terdapat gambaran cor dan pulmo dalam batas normal pasca menjalani observasi dan pengobatan simtomatis

Pada tanggal 15 Juni 2018 pasien kembali kontrol ke poliklinik kondisi klinis tanpa keluhan. Hasil pemeriksaan fisik dalam batas normal. Observasi tetap dilanjutkan hingga pasien melahirkan.

Pasien melahirkan pada tanggal 27 Juli 2018 secara spontan pervaginam tanpa komplikasi. Dua bulan setelah melahirkan (19/9/2018) pasien melakukan kontrol kembali ke poliklinik paru dan didapatkan pemeriksaan fisik dalam batas normal dengan hasil foto toraks ekspansi sempurna paru kanan dan kiri (Gambar 3).

\section{PEMBAHASAN}

PS pada kehamilan merupakan kasus yang jarang terjadi di dunia. Epidemiologi hingga kini belum diketahui, namun diperkirakan hingga tahun 2013 terdapat sekitar 57 kasus PS pada kehamilan. ${ }^{2}$ Pada kasus ini, dilaporkan seorang ibu dengan kehamilan kelima trimester I berusia 28 tahun dengan Pneumotoraks Spontan Primer (PSP) berulang. Beberapa kasus PS pada kehamilan yang telah dilaporkan terlihat adanya variasi karakteristik ibu dan usia kehamilan. Laporan kasus dan tinjauan pustaka yang ditulis oleh Garg dkk tahun 2008 menyebutkan bahwa, rata-rata usia ibu yang mengalami pneumotoraks pada kehamilan adalah 26,4 tahun. ${ }^{4}$ Usia tersebut serupa dengan usia wanita tidak hamil yang berisiko tinggi mengalami PS, yaitu usia 20-30 tahun. Pada Mohammadi dkk tahun 2011 melaporkan bahwa 53,3\% kasus terjadi pada masa perinatal dan $46,7 \%$ kasus terjadi selama 
trimester pertama dan kedua. ${ }^{6}$ Pada serial kasus dan tinjauan pustaka yang ditulis oleh Akcay dkk tahun 2013 mendapatkan bahwa rata-rata kasus PS pada kehamilan terjadi pada ibu hamil dengan gravida satu atau dua. ${ }^{7}$ Fakta epidemiologi tersebut berbeda dengan karakteristik kasus pada laporan ini, yaitu kasus PS yang terjadi pada gravida kelima.

Terdapat tiga kondisi patologis yang dapat menimbulkan pneumotoraks, yaitu 1) adanya ruang penghubung antara alveoli dan pleura; 2) hubungan langsung dan tidak langsung antara atmosfer dan ruang pleura; 3) adanya organisme penghasil gas di dalam ruang pleura. PSP merupakan pneumotoraks yang tejadi tanpa adanya faktor pencetus yang jelas. Pada artikel yang ditulis oleh Noppen M dkk tahun 2002 adanya ruang penghubung antara alveoli dan pleura yang diakibatkan oleh pecahnya bleb atau bula subpleura secara spontan merupakan proses patologis awal terjadinya PS. ${ }^{8}$ Pecahnya bleb atau bula subpleura secara spontan sebagian besar dipicu oleh kondisi yang dapat meningkatkan tekanan intratorakal, seperti manuver valsava, batuk, muntah, perubahan tekanan atmosfer, hingga mendengarkan musik dengan volume tinggi. ${ }^{9} 10$ Pada ibu hamil, PSP dapat dipicu oleh beberapa keadaan khusus seperti, hiperemesis gravidarum serta keadaan mengedan ketika proses persalinan. Pada serial kasus dan tinjauan pustaka yang ditulis oleh Lal dkk, tahun 2007 disebutkan bahwa pola pernapasan yang cepat saat kehamilan yang berhubungan dengan peningkatan konsumsi oksigen sebesar $20 \%$ pada masa antepartum dan $50 \%$ ketika proses persalinan juga dapat meningkatkan risiko pecahnya bula atau blep sub-pleura. ${ }^{11,12}$ Pada kasus diatas, pasien merasa sesak serta nyeri dada setelah mengalami muntah yang hebat, dan pasien juga sedang menjalani terapi hiperemesis gravidarum, sehingga kondisi tersebut memiliki probabilitas yang tinggi sebagai faktor pemicu terjadinya PSP. Pneumotoraks Spontan Sekunder (PSS) juga dapat terjadi pada beberapa kasus kehamilan. Riwayat asma, penggunaan kokain, infeksi paru seperti tuberkulosis, dan LAM harus dipikirkan sebagai faktor penyebabnya. Pada kasus diatas, tidak terdapat riwayat penyakit paru ataupun tanda adanya infeksi paru sebelumnya, sehingga kemungkinan terjadinya PSS dapat disingkirkan. ${ }^{3}$

Proses pembentukan bleb atau bula subpleura pada paru hingga saat ini belum diketahui secara pasti. Pada beberapa kasus juga ditemukan adanya porositas pleura sebagai penyebab terjadinya PS selain pecahnya bleb atau bula subpleura. Porositas pleura merupakan area pada pleura viseral yang mengalami kerusakan sel mesotelia sehingga digantikan oleh lapisan elastofibrotik dengan peningkatan porositas, sehingga memudahkan terjadinya aliran udara ke ruang pleura. Terdapat beberapa faktor risiko terbentuknya bleb atau bula subpleura, yaitu inflamasi saluran pernapasan distal seperti ekstensif bronkiolitis pada perokok, predisposisi hereditas, abnormalitas bronkus, ectomorphic physiocnomy dengan tekanan intrapleura yang lebih negatif, iskemia apikal, Indeks Masa Tubuh (IMT) rendah dan restriksi kalori, serta abnormalitas jaringan ikat. ${ }^{1}$ Penelitian yang dilakukan oleh Amjadi dkk tahun 2007 mendapatkan bahwa perokok aktif dan pasif dengan IMT $<22 \mathrm{~kg} / \mathrm{m}^{2}$ memiliki risiko yang lebih tinggi untuk terbentuknya bleb atau bulla subpleura. ${ }^{13}$ Penelitian tersebut memberikan hipotesis bahwa individu dengan IMT rendah memiliki lapisan adiposa pleura visceral yang lebih tipis sehingga memudahkan terbentuknya bleb atau bulla. Lapisan pleura pada apeks paru juga disebutkan lebih tipis dibandingkan bagian lainnya, hal tersebut dipercaya sebagai penyebab bleb atau bulla subpleura dominan terbentuk pada apeks paru. Pasien pada laporan ini merupakan seorang perokok pasif dan memiliki IMT $18,9 \mathrm{~kg} / \mathrm{m}^{2}$. Fakta tersebut menunjukkan bahwa pasien pada kasus ini memiliki faktor risiko terbentuknya bleb atau bulla bila dilihat berdasarkan riwayat terpajan asap rokok lingkungan dan IMT.

Gejala klinis pneumotoraks pada kehamilan serupa dengan pneumotoraks secara umum. Sesak dan nyeri dada pleuritik merupakan keluhan utama ibu hamil dengan pneumotoraks. Sebagian besar pasien dengan PSP mengalami gejala nyeri dada ipsilateral yang membaik dalam 24 jam. $^{8}$ Sesak dapat terjadi namun ringan. Pemeriksaan fisik dapat normal pada pneumotoraks yang kecil, namun pada pneumotoraks luas didapatkan penurunan suara penapasan dan taktil fremitus, hipersonor pada perkusi, hipotensi, takipnea, takikardia, dan sianosis. ${ }^{1}$ Pada kasus ini, pasien datang ke poliklinik paru dengan keluhan utama sesak dan nyeri dada yang memberat ketika menarik napas sejak lima hari yang lalu dan keluhan dirasakan telah membaik pada saat pasien datang ke poliklinik. Saat mengalami keluhan, pasien masih dapat menjalankan aktifitas sehari-hari. Pada pemeriksaan fisik didapatkan hemodinamik stabil dengan SpO2 98\%, gerakan paru simetris dengan penurunan suara napas paru kanan dan perkusi hipersonor paru kanan. Berdasarkan gejala klinis dan pemeriksaan fisik, dapat diketahui bahwa gangguan ventilasi yang terjadi pada pasien mengalami perbaikan dengan observasi yang sesuai dengan perjalanan klinis PSP.

Penegakkan diagnosis pneumotoraks dilakukan melalui anamnesis dan konfirmasi pemeriksaan penunjang. Mayoritas kasus pnemotoraks dapat dikonfirmasi melalui pemeriksaan foto toraks posteroanterior (PA). Pemeriksaan tersebut juga 
dapat digunakan untuk mengetahui luas area pleura yang terisi udara serta tingkat keparahan kolaps paru sehingga dapat menjadi pertimbangan pemberian terapi. Pada kasus PSP yang kecil, pemeriksaan pindai CT menjadi pilihan dalam menegakkan diagnosis. ${ }^{1}$ Pada pasien dalam laporan kasus ini, telah dilakukan dua kali pemeriksaan foto toraks PA, yaitu pada tanggal 13 Januari 2018 dengan hasil pneumotoraks dekstra ipsilateral dan pada tanggal 27 Januari 2018 yang menunjukkan pneumotoraks dekstra ipsilateral dengan ekspansi paru yang lebih baik dibandingkan rontgen sebelumnya ( $<20 \%$ hemitoraks). Pemeriksaan penunjang lainnya yang telah dilakukan oleh pasien juga menunjukkan adanya retriksi paru sedang yang menunjang diagnosis pneumotoraks.

Pemeriksaan radiografi dada pada kehamilan memiliki risiko radiasi ion yang tinggi khususnya pada usia delapan minggu yang merupakan tahap organogenesis. Pada penggunaannya harus dipikirkan antara kemungkinan risiko yang ditimbulkan dengan manfaat yang didapatkan ketika melakukan pemeriksaan tersebut. ${ }^{14}$ Mengingat radiografi dada merupakan pemeriksaan penunjang untuk menegakkan pneumotoraks, sehingga manfaat yang didapat lebih tinggi dibandingkan kemungkinan risiko yang terjadi terutama bila menggunakan alat pelindung radiasi abdomen.

Pada penelitian dan tinjauan pustaka yang dilakukan oleh Tanase dkk tahun 2007 disebutkan bahwa hingga saat ini pemilihan terapi pneumotoraks pada kehamilan masih kontroversial. ${ }^{15}$ Berdasarkan tinjauan pustaka pada 44 kasus, pola pemilihan terapi inisiasi pada PSP dalam kehamilan adalah sebagai berikut, observasi dilakukan pada $22,7 \%$ kasus (10/44), tube thoracostomy pada $75 \%$ (33/44), dan torakotomi pada 2,3\% (1/44). Serial kasus yang ditulis oleh Lal dkk pada tahun 2007 menunjukkan pola pemilihan terapi yang serupa, yaitu hanya sembilan pasien dilakukan observasi tanpa aspirasi, 16 pasien dilakukan drainase dada, dan 19 pasien memerlukan intervensi bedah yang sebagian besar dilakukan pada masa post partum. ${ }^{11}$ Pada laporan kasus yang yang ditulis oleh Garg dkk tahun 2008 menyebutkan bahwa observasi ketat dilakukan pada kehamilan dengan pneumotoraks yang kecil ( $\leq 20 \%$ hemitoraks) dan tube thoracostomy harus dilakukan padapneumotoraks luas (> 20\% hemitoraks). ${ }^{4}$ Terdapat indikasi dilakukannya reseksi bleb atau bula dan pleurodesis melalui torakoskopi pada kasus pneumotoraks berulang atau persisten. Penggunaan torakoskopi saat ini lebih dipilih dibandingkan torakotomi karena beberapa manfaat yang diberikan, yaitu 1) waktu paparan anastesi yang lebih singkat; 2) ekspansi paru yang cepat ; 3) nyeri post-operatif yang lebih ringan; 4) lama rawat yang lebih singkat. Pada kasus ini, setelah dilakukan pemeriksaan klinis, melihat hasil pemeriksaan penunjang, serta pertimbangan kondisi janin dan kenyamanan pasien diputuskan untuk melakukan observasi di rumah selama sepuluh hari. Ditemukan perkembangan klinis dan penunjang yang signifikan setelah observasi selama dua minggu. Setelah dilakukan observasi kembali pada satu minggu selanjutnya ditemukan pemeriksaan klinis dalam batas normal. Kondisi pasien pada pemeriksaan terakhir (26 April 2018) menunjukkan kondisi yang stabil. Hal tersebut menunjukkan keberhasilan observasi pada pasien. Observasi kondisi pasien harus dilakukan secara rutin mengingat tingginya risiko kejadian ulang SP pada ibu hamil khususnya pada masa persalinan.

Pada kasus ini, ibu hamil sukses menjalani persalinan spontan pervaginam tanpa komplikasi. Saat dilakukan observasi setelah persalinan, tidak ditemukan tanda-tanda pneumotroraks. Sebagian besar kasus ibu hamil dengan pneumotoraks menunjukkan kesuksesan menjalani persalinan spontan pervaginam, hanya 17,3\% kasus memerlukan intervensi operasi caesaria, dan 1,9\% mengalami kematian janin. ${ }^{4}$ Berdasarkan atas artikel yang ditulis oleh Karadas dkk tahun 2014, proses persalinan spontan pervaginam aman dilakukan pada pasien yang telah menerima terapi efektif untuk pneumotoraks. Operasi Caesar dengan anastesi umum harus dihindari karena ventilasi tekanan positif dapat menyebabkan terjadinya tension pneumotoraks. Beberapa literatur menyebutkan bahwa pendekatan metode terminasi yang paling aman untuk ibu hamil dengan riwayat pneumotoraks adalah elective assisted deliveries, salah satunya melalui persalinan dengan forcep untuk memperpendek kala dua persalinan. ${ }^{11}$ Pneumotoraks bukan sebuah indikasi absolut untuk operasi Caesar dan pada situasi ini, pilihan pasien merupakan hal yang dapat dipertimbangkan. Bila terdapat situasi emergensi obstetri dan mengharuskan dilakukannya operasi caesaria, tindakan dilakukan dengan anastesi spinal. ${ }^{16}$

Pada tinjauan pustaka 41 kasus kehamilan dengan pneumotoraks oleh Gorospe dkk tahun 2002 didapatkan terjadi resolusi sempurna pada $78 \%$ kasus pneumotoraks dengan observasi dan $40 \%$ kasus yang ditangani dengan torakostomi. ${ }^{17,18}$ Laporan kasus dan tinjauan pustaka oleh Sathiyathasan menyebutkan bahwa pada beberapa studi sebelumnya menunjukkan adanya risiko yang tinggi kejadian ulang pneumotoraks pada masa antepartum dan intrapartum pada pasien dengan riwayat pneumotoraks. Risiko kejadian ulang pneumotoraks pada pasien ketika masa persalinna diperkirakan sebesar 30\%. Risiko kejadian ulang SP setelah episode awal adalah 30\% dengan risiko kejadian ulang selanjutnya adalah $50 \%$ dan risiko kejadian ulang secara umum adalah 33\%-44\%. ${ }^{19}$ 
Prognosis ibu dan janin pada kehamilan dengan pneumotoraks adalah baik.

\section{KESIMPULAN}

Pneumotoraks adalah salah satu diagnosis yang harus dipikirkan ketika terdapat keluhan sesak dan nyeri dada pada ibu hamil khususnya ibu hamil dengan Hiperemesis Gravidarum. Pemilihan terapi disesuaikan dengan penyebab, tingkat keparahan gejala, risiko tindakan, serta kenyamanan pasien. Adanya risiko hipoksia pada ibu dan janin yang tinggi menyebabkan observasi ketat serta edukasi kepada pasien merupakan hal yang sangat penting.

\section{DAFTAR PUSTAKA}

1. Noppen M. Spontaneous Pneumothorax: Epidemiology, Pathophysiology And Cause. Eur Respir Rev. 2010; 19:117: 217-219.

2. Gupta M, Bonnington J, Gallagher F, Widekind V. Spontaneous Pneumothorax- A Rare Complication of Labour. RCOG World Congress. United Kingdom. 2013.

3. Revicky V, Simpson P, Fraser D. Postpartum pneumomediastinum: An uncommon cause for chest pain. Obstet Gynecol Int. 2010: 2010; 956142.

4. Garg R, Sanjay, Das V, Usman K, Rungta S, Prasad R. Spontaneous Pneutomthorax: An unusual complication of pregnancy - A case report and a review of literature. Ann Thorac Med. 2008; 3(3):104-105.

5. Pinto RM, Mahankali S, Prasanna BS, Ramkumar MM. Spontaneous Pneumothorax in Pregnancy: A Challenge for Anaesthesiologist. Journal of Obstetric Anaesthesia and Critical Care. 2017; 7(2):106-108

6. Mohammadi A, Rad MG, Afrasiabi K. Spontaneous pneumothorax in pregnancy: a case report. Tuberk Toraks. 2011; 59(4):396-398.

7. Akcay O, Uysal A, Samancilar O, Ceylan KC, Sevinc C, Kaya SO. An unusual emergency condition in pregnancy: pneumothorax. Case series and review of the literature. Arch Gynecol Obstet. 2013; 287(2):391-394.
8. Noppen M, Schramel F. Pneumothorax. Eur Respir. 2002; 22: $279-296$.

9. Alifano M, Parri SNF, Bonfanti B, Arab WA, Passini A, Boaron M, Roche N. Atmospheric Pressure Influences the Risk of Pneumothorax. Chest. 2007; 131:1877-1882.

10. Noppen M, Verbanck S, Harvey J, et al. Music: a new cause of primary spontaneous pneumothorax. Thorax. 2004; 59: $722-724$.

11. Lal A, Anderson G, Cowen M, Lindow S, Arnld AG. Pneumotorax and Pregnancy. Chest. 2007; 132:1044-1048.

12. Hamid MFA, Aziz H, Ian SC, Lin ABY. Recurrent spontaneous pneumothorax during pregnancy managed conservatively: a case report. Med J Malaysia. 2016; 71(2):93-95.

13. Amjadi K, Alvares GG, Vanderhelst E, Velkeniers B, Lam M, Noppen M. The Prevalence of Blebs or Bullae among Young Healthy Adults. Chest. 2007; 132:1140-1145.

14. Karadas S, Okyay AG, Odabasi D, Selvi F. Spontaneous pneumothorax and pneumomediastinum in pregnancy: A case report. J Turk Soc Obstet Gynecol 2014; 2:131-33

15. Tanase Y, Yamada T, Kawaryu Y, Yoshida M, Kawai S. A Case of Spontaneous Pneumothorax during Pregnancy and Review of the Literature. Kobe J. Med. Sci. 2007; 53(5):251-255.

16. Wong MK, Leung WC, Wang JK, Lao TT, Ip MS, Lam WK, dkk. Recurrent pneumothorax in pregnancy: what should we do after placing an intercostal drain. Hong Kong Med. 2006; 12:375-80.

17. Gorospe L, Puente S, Madrid C, Novo S, Gil-Alonso J, Guntinas A. Spontaneous pneumothorax during pregnancy. SouthMed J. 2002; 95:555-8.

18. Nwaejike N, Elbur E, S Kandadai, Rammohan, Shah R. Should pregnant patients with a recurrent or persistent pneumothorax undergo surgery? Interactive Cardiovaskuler and Thoracic Surgery. 2013:1-3.

19. Vinay KA, RAghukant A. 2014. Recurrent Spontaneous Pneumothorax in Pregnancy. Indian J Chest Dis Allied Sci. 2014; 56:33-35.

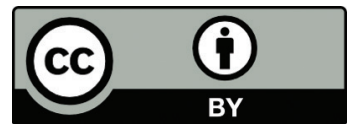

This work is licensed under a Creative Commons Attribution 